\title{
Analysis of Fatigue and Fracture of Hot Mix Asphalt Mixtures
}

\author{
Mohammad Jamal Khattak ${ }^{1}$ and Gilbert Y. Baladi ${ }^{2}$ \\ ${ }^{1}$ Department of Civil Engineering, University of Louisiana at Lafayette, Lafayette, LA 70504-2291, USA \\ ${ }^{2}$ Pavement Research Center of Excellence, Department of Civil and Environmental Engineering, \\ Michigan State University, 3546 Engineering Building, East Lansing, MI 48824, USA \\ Correspondence should be addressed to Mohammad Jamal Khattak; khattak@louisiana.edu
}

Received 12 November 2012; Accepted 19 December 2012

Academic Editors: M. Garg, H.-L. Luo, B. Uy, and J. Zheng

Copyright (C) 2013 M. J. Khattak and G. Y. Baladi. This is an open access article distributed under the Creative Commons Attribution License, which permits unrestricted use, distribution, and reproduction in any medium, provided the original work is properly cited.

\begin{abstract}
An accurate assessment of the fatigue life of hot mix asphalt (HMA) mixtures depends on the criteria used in the fatigue analysis. In the past, various studies have been conducted on crack initiation and crack propagation of the HMA mixtures. Most of these studies were focused on the beam samples with or without a sawed crack at the bottom. This paper presents and discusses two different fatigue life criteria for two-dimensional problems represented by cylindrical samples. One criterion is based on the rate of accumulation of the tensile horizontal plastic deformation (HPD) as a function of the number of load repetitions. The second criterion is based on fracture mechanics, stress intensity factor, and the rate of crack growth with respect to the number of load repetitions. It was found that, because of three-dimensional nature of the crack growth in cylindrical samples, the Paris' law was violated. It is shown that the rate of crack growth criterion provides higher values of fatigue life relative to the rate of accumulation of HPD criterion. Although a trend could be established among the fatigue lives obtained by using the two criteria, it was found that the fatigue lives obtained from the rate of accumulation of HPD were consistent and based on the actual measurement of HPD for HMA mixtures.
\end{abstract}

\section{Introduction}

The prediction of fatigue life of hot mix asphalt mixtures (HMA) is an important aspect of pavement design. Fatigue cracks are caused by repeated traffic loading and are typically initiated at the bottom of the HMA layer where the tensile stress and strain are the highest. With increasing number of load application, the cracks propagate to the surface where they appear as one or more longitudinal cracks, which will be connected by transverse cracking to form a pattern similar to an alligator hide. Many factors affect the fatigue life of HMA pavement such as the tensile strength of the asphalt binder, traffic load, construction practices, aggregate angularity and gradation, relative stiffness of the AC, and the base material and environmental conditions such as temperature and moisture.

In the past, many efforts have been made to estimate the fatigue life of laboratory compacted HMA mixtures. Such estimates are highly dependent on the criterion used. Hence, various criteria were developed and are reported in the literature [1-12]. Monismith and Deacon (1969) [6] and Pell and Cooper (1975) [7] conducted displacementcontrolled trapezoidal fatigue test and proposed that for HMA mixtures the fatigue failure of the mixture is reached when the load value drops to a half of the initial load value. On the other hand for a stress-controlled fatigue test, the failure (i.e., fatigue life) was reached when the displacement value doubles the initial displacement value [11]. The damage failure criterion was used based on the analysis of the stiffness modulus, $E$, values along the number of load cycles. It was observed that the stiffness modulus decreases rapidly as the load application progresses. After this, a linear decrease of the stiffness modulus was reported. Finally, a rapid loss of stiffness modulus occurred which was related to crack development [9-11]. Hence, the fatigue life was defined as the number of load cycles at which the rapid increase in stiffness modulus occurred. Similarly, for a displacement or stress controlled test, the change in the displacement or stress along the repeated loading was plotted. Based on this criterion, the HMA specimen failed when the displacement or stress values 
TABLE 1: Sample characteristics and sample geometry for fatigue testing.

\begin{tabular}{lcccc}
\hline Mixtures & $\begin{array}{c}\text { Test temperature } \\
\left({ }^{\circ} \mathrm{C}\right)\end{array}$ & $\begin{array}{c}\text { Average percent } \\
\text { air voids }\end{array}$ & $\begin{array}{c}\text { MDOT } \\
\text { specification }\end{array}$ & $\begin{array}{c}\text { Diameter } \\
(\mathrm{mm})\end{array}$ \\
\hline $\begin{array}{l}\text { AC5 and AC10 straight mixtures } \\
\text { AC5 and AC10 polymer-modified } \\
\text { asphalt mixtures }\end{array}$ & 25 & 3.50 & $4 \mathrm{C}$ & $\begin{array}{c}\text { Thickness } \\
(\mathrm{mm})\end{array}$ \\
$\begin{array}{l}\text { MDOT AC mixture without slot } \\
\text { MDOT AC mixture with slot }\end{array}$ & 25 & 3.75 & $4 \mathrm{C}$ & 63.5 \\
$(25 \mathrm{~mm} \times 2.5 \mathrm{~mm})$ & 20 & 7.50 & $4 \mathrm{~B}$ & 63.5 \\
\hline
\end{tabular}

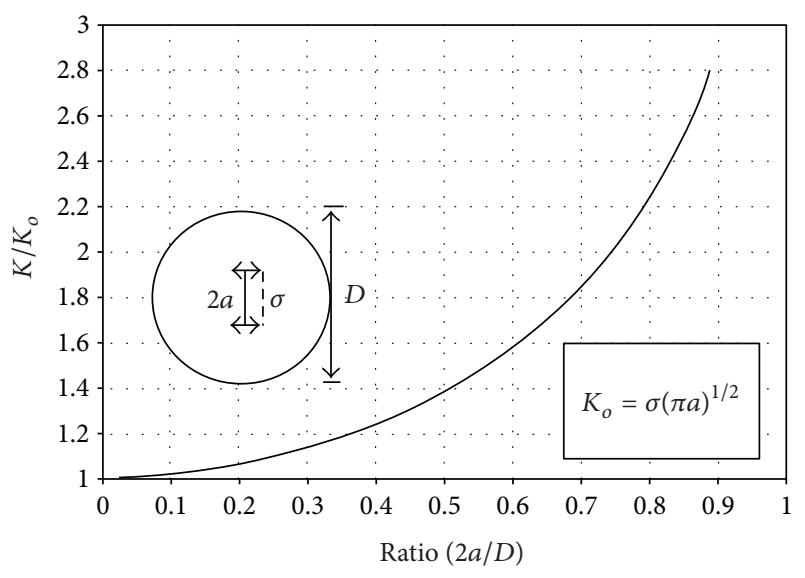

FIGURE 1: Stress intensity factor $(K)$ for a centrally cracked circular plate (after [13]).

exhibited an accelerated increase while the loading process progressed $[8,11,12]$.

In this paper, a comparison between two different fatigue life criteria for two-dimensional problems represented by cylindrical samples is discussed and presented. One criterion is based on the rate of accumulation of the tensile horizontal plastic deformation (HPD) as a function of the number of load repetitions. The other criterion is based on fracture mechanics and takes into account stress intensity factor and the rate of crack growth with respect to the number of load repetitions.

\section{Materials and Methods}

Different types of HMA mixtures were constructed tested during this study. These include the following.

\subsection{AC5 and AC10 Straight and Polymer-Modified Asphalt} (PMA) HMA Mixtures. The mix design for these mixtures was based on the standard Marshall Mix design procedure with 50 blows on each side of cylindrical samples. The samples were $10.16 \mathrm{~cm}$ in diameter and $6.35 \mathrm{~cm}$ thick. The Michigan Department of Transportation (MDOT) specifications of voids in mineral aggregates (VMA) and other criteria for the MDOT designated 4C HMA mixtures were followed. The polymers used for HMA modification included styrenebutadiene-styrene (SBS), styrene-ethylene-butylene-styrene
(SEBS), and styrene-butadiene-rubber (SBR). Detailed information regarding the mix design and polymer-modified asphalt mixtures can be found in [5].

2.2. MDOT HMA Mixtures. These mixtures were obtained from construction sites by MDOT and were compacted at the Michigan State University laboratory. Cylindrical samples of $150 \mathrm{~mm}$ diameter and $76 \mathrm{~mm}$ thick were compacted under the pressure of $600 \mathrm{KPa}$ using Gyratory compactor. MDOT specifications of VMA and other criteria for the asphalt mixtures were followed for these mixtures. The compacted samples were cut into two $35 \mathrm{~mm}$ thick samples using watercooled diamond saw. For some samples, a slot $(25 \mathrm{~mm} \times$ $2.5 \mathrm{~mm}$ ) was also made at the center of the sample along the vertical diameter. Samples with a slot in the center were tested under dynamic loading.

All samples were subjected to cyclic loads at 20 and $25^{\circ} \mathrm{C}$ using indirect tensile cyclic load tests. First, the sample was subjected to a sustained stress of $13 \mathrm{KPa}$. When the sample came to rest, a cyclic stress of $75 \mathrm{KPa}$ was applied, and the deformation of the sample was measured in three directions using linear variable differential transducers (LVDTs). Each loading cycle consisted of 0.1 second load-unload time and 0.4 second of rest period. The resilient and total moduli of the mixtures were calculated using the resilient and total deformations, respectively [4]. The sample characteristics and sample geometry are listed in Table 1.

\section{Fatigue Life Criteria}

The fatigue life of each test sample was analyzed using two fatigue life criteria. One criterion is based on the rate of accumulation of tensile horizontal plastic deformation (HPD) with respect to the number of load repetitions. The other is based on fracture mechanics, and it takes into account the rate of crack growth with respect to the number of load repetitions. Both criteria are discussed below.

3.1. The Rate of Accumulation of HPD Criterion. This criterion was developed at Michigan State University, and it has been used in several research studies [5]. In this criterion, it was hypothesized that, at certain number of load application, microcracks are initiated in the sample. With increasing number of load repetitions, they grow to macrocracks that can be visually detected. Once the microcracks are initiated and interconnected, the tensile horizontal plastic deformation 


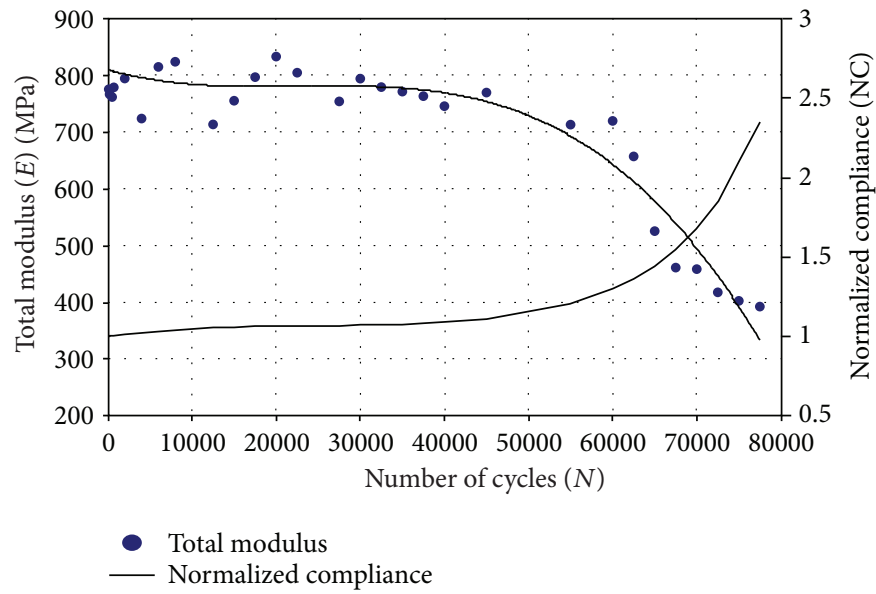

FIGURE 2: A typical plot of the total modulus and normalized compliance versus the number.

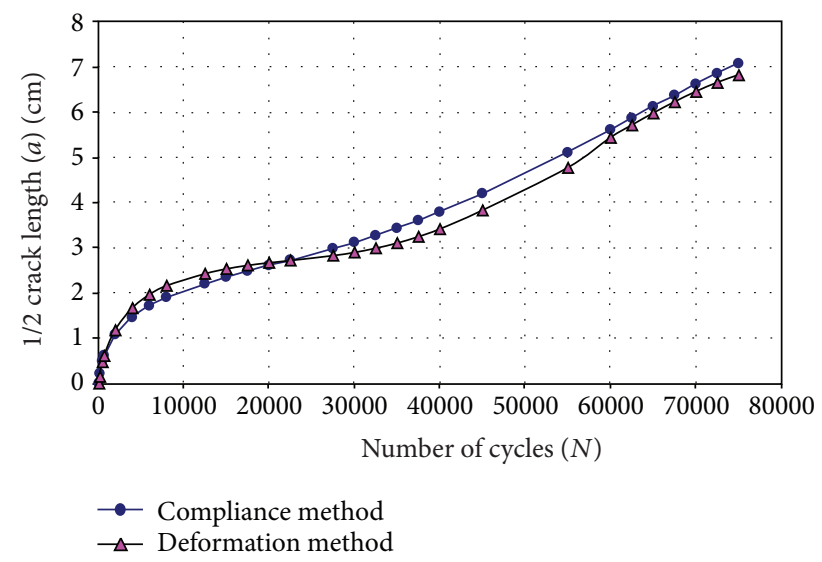

FIGURE 3: A typical plot of the crack length as a function of the number of load repetitions.

starts to increase sharply, as a result of stress concentration at the crack tips. Therefore, in this hypothesis, the fatigue life of a test sample is defined as the number of cycles at which the rate of accumulation of HPD increases. Based on the definition, the following procedure was established for the determination of the fatigue lives of the test samples.

(1) From the test results, the cumulative HPD (HPD $)_{N}$ is plotted as a function of the number of load repetition $(N)$. A polynomial equation is fitted to the test results such that

$$
(\mathrm{HPD})_{N}=\sum_{i=1}^{N} \Delta p_{i}=f(N)
$$

where $\Delta p_{i}$ is the horizontal plastic deformation per load cycle.

(2) The rate of accumulation of HPD (RHPD) ${ }_{N}$ is obtained by differentiating the above equation with respect to the number of load repetition $(N)$ as shown below:

$$
(\mathrm{RHPD})_{N}=\frac{d(\mathrm{HPD})_{N}}{d(N)}=f^{\prime}(N)
$$

(3) The normalized rate of accumulation of HPD $(\mathrm{NRHPD})_{N}$ at any load cycle is calculated as

$$
(\mathrm{NRHPD})_{N}=\frac{(\mathrm{RHPD})_{N}}{(\mathrm{RHPD})_{100}},
$$

where (RHPD) ${ }_{100}$ is the rate of accumulation of the HPD at 100th load cycle.

(4) The normalized rate of accumulation of HPD is then plotted on a semilogarithmic scale as a function of the number of load repetition $(N)$.

The slope of the curve decreases first, reaches a valley, and then starts to increase. The decrease in the normalized rate of accumulation of HPD at the beginning of the test is due to slight densification and sample seating. However when cracks are initiated, the normalized rate of accumulation of HPD also increases. Hence, in this procedure, the fatigue life is defined as the number of load repetitions at which the rate of accumulation of HPD starts to increase.

3.2. The Rate of Crack Growth Criterion. The asphalt concrete is a heterogeneous material consisting of asphalt cement and fine and coarse aggregates. The fatigue cracks initiation in composite and heterogeneous material is related to the preexisting internal flaws. In HMA mixtures these internal flaws exist in the form of air voids, surface irregularities, and internal defects. These internal flaws are randomly distributed in the HMA mixtures and control the geometry and propagation of fatigue cracks. The rate of crack growth criterion utilizes the concepts of fracture mechanics to relate the fatigue life to the rate of crack growth and stress intensity factor. With increasing number of load repetition the preexisting microcracks (internal flaws) at a given state 


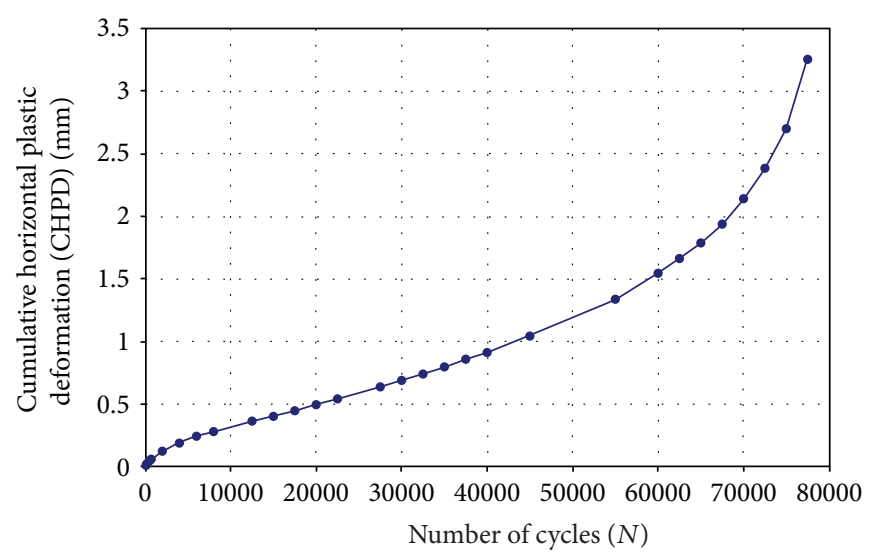

FIgURE 4: A typical plot of cumulative HPD as a function of the number of load repetitions.

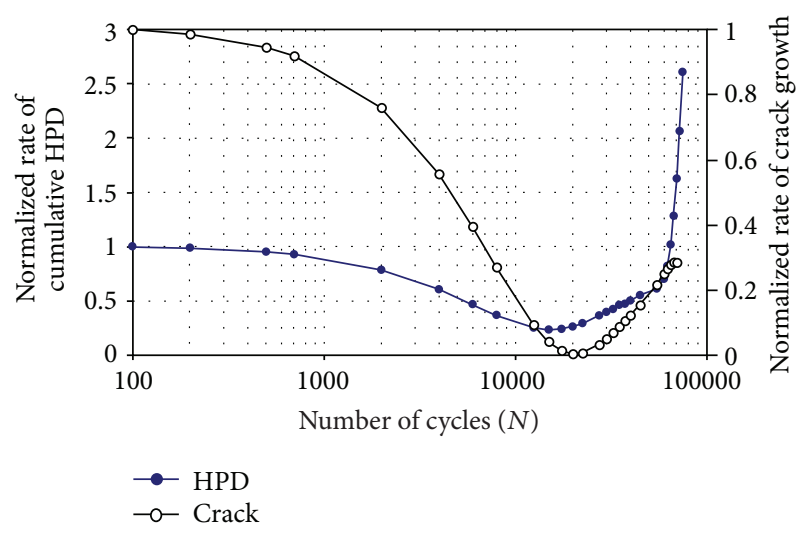

Figure 5: A typical plot of normalized rate of the rate of the crack growth and cumulative HPD as a function of the number of load repetitions.

of stress start to propagate and reach critical dimensions and pattern where the rate of crack propagation increases. The number of load repetitions at which the rate of crack growth increases is designated as the fatigue life of the HMA mixtures. The following two approaches were investigated to indirectly determine the crack length and growth.

Method of Compliance. In this fatigue life criterion an indirect method was utilized to estimate the crack length at different load repetitions. The indirect method of crack length was utilized because it is not possible to get actual measurement of the crack length in a cylindrical sample subjected to indirect tensile cyclic loading. The indirect method is based on the fact that as the crack length increases from an initial flaw, the compliance $(C)$ of the sample also increases due to stress concentration in the vicinity of the crack tip. The compliance (C) of a material subjected to load is defined as the reciprocal of modulus and is given by the following equation [14]:

$$
C=\frac{1}{E}
$$

If the material behaves elastically, the increase in compliance is related to the crack length. The increase in the compliance as a result of crack growth is expressed by Irwin's equation as follows $[13,15]$.

$$
\frac{\partial \mathrm{C}}{\partial a}=\frac{2}{E}\left(1-\mu^{2}\right) \frac{K^{2}}{P^{2}},
$$

where $C=$ compliance; $E=$ Young's modulus; $a=$ crack length; $K=$ stress intensity factor, $P=$ load per unit thickness; $\mu=$ poisson ratio.

This equation can also be written as

$$
\Delta C=\frac{2\left(1-\mu^{2}\right)}{E} \frac{K^{2}}{P^{2}} \Delta a .
$$

The stress intensity factor can be obtained as follows [16]:

$$
\begin{gathered}
K=\beta \sigma \sqrt{\pi a} \\
\sigma=\frac{2 P}{\pi D},
\end{gathered}
$$

where $\sigma$ is an applied stress, $D$ is a diameter of the sample, $P$ is the load per unit thickness, and $\beta$ is a shape factor and is a function of $a / D$ ratio as shown in Figure 1 [17].

Substituting $\sigma$ in (3) and rearranging, the equation for $K^{2} / P^{2}$ yields the following equation:

$$
\frac{K^{2}}{P^{2}}=\frac{4 a \beta^{2}}{\pi D^{2}}
$$

If the initial compliance $\left(C_{o}\right)$ and the initial crack length $\left(a_{o}\right)$ are known, normalized compliance $(\mathrm{NC})$ at any number of load application can be calculated from (6) as follows:

$$
\begin{aligned}
& C-C_{o}=\frac{2\left(1-\mu^{2}\right)}{E_{o}} \frac{K^{2}}{P^{2}}\left(a-a_{o}\right), \\
& C=C_{o}+\frac{2\left(1-\mu^{2}\right)}{E_{o}} \frac{K^{2}}{P^{2}}\left(a-a_{o}\right) .
\end{aligned}
$$

Normalizing relative to $C_{o}$ yields

$$
\frac{C}{C_{o}}=N C=1+2\left(1-\mu^{2}\right) \frac{K^{2}}{P^{2}}\left(a-a_{o}\right) .
$$




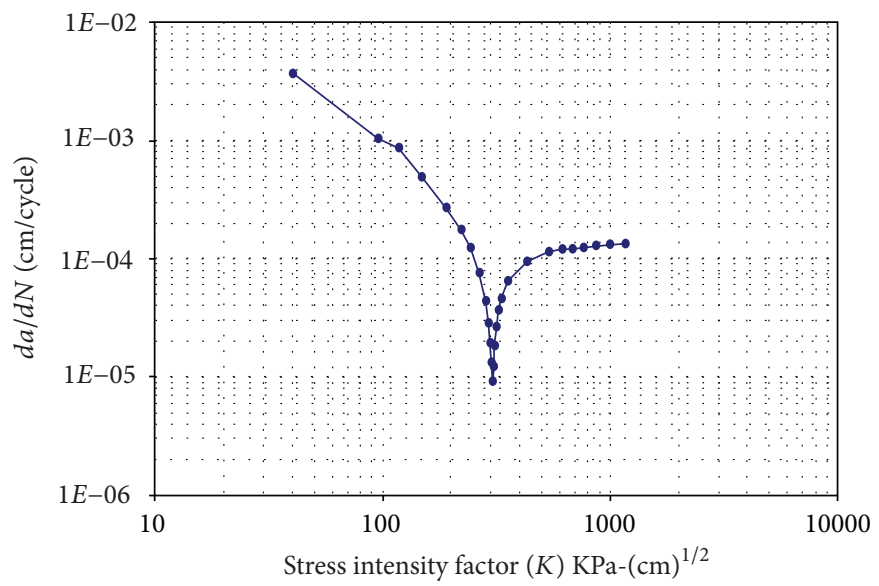

FIGURE 6: A typical $K-d a / d N$ curve for indirect tensile specimen of asphalt concrete mixtures.

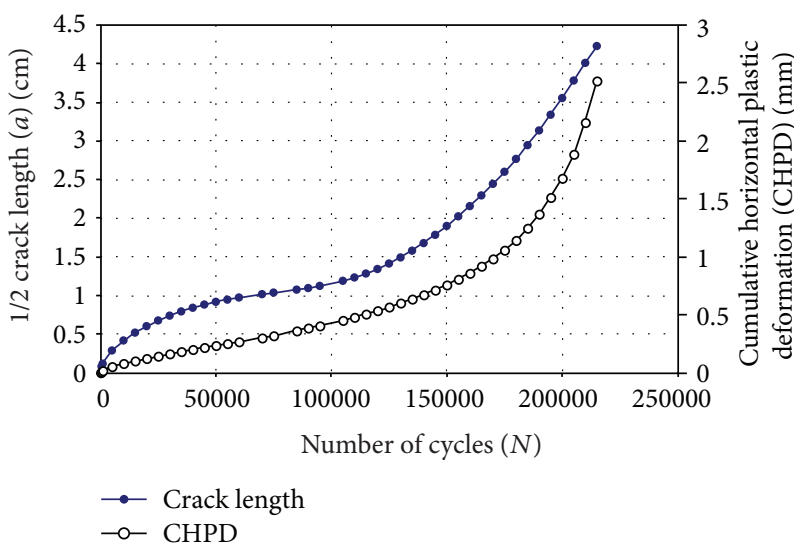

FIGURE 7: Half-crack length and cumulative HPD as a function of the number of load repetitions for AC10-2\% SBR mixture.

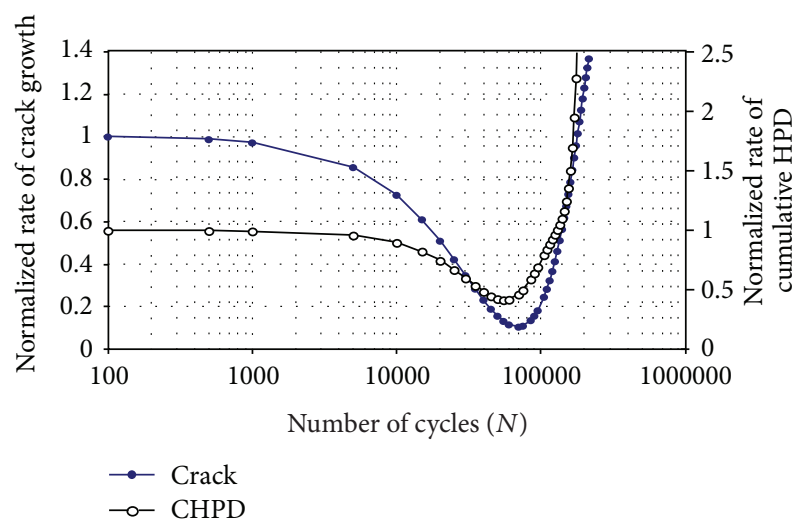

FIGURE 8: Normalized rate of crack growth $(d a / d N)$ and rate of cumulative HPD $(d(\mathrm{CHPD}) / d N)$ for AC10-2\% SBR.

Equation (11) gives the relation between the compliance and the crack length. From indirect cyclic load test, the compliance of a sample can be calculated at different cycles by simply taking the inverse of the total modulus $(E)$. From

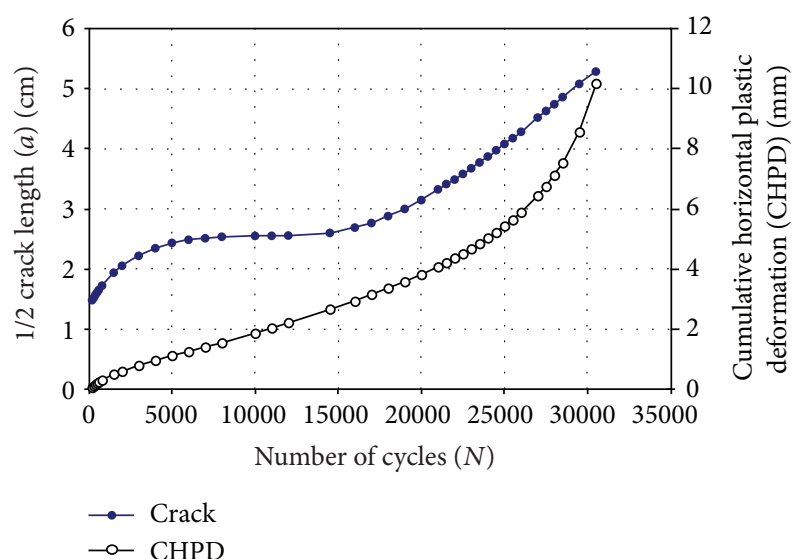

FIGURE 9: Half-crack length and cumulative HPD as a function of the number of load repetitions for MDOT AC mixture with slot at the center.

this, the normalized compliance can be calculated by dividing all the data points with the compliance value at the 100th load cycle. Hence the crack length at a given load cycle can be obtained by using (11). Once the crack length is known, the stress intensity factor $(K)$ can be calculated from (7).

The crack length as a function of number of cycles can also be calculated using another fracture mechanics technique that utilizes the vertical displacement of the sample. This technique provides a check for the crack length calculations using the compliance technique. The method of displacement is explained below.

Method of Displacement. With the increase in number of load cycles the crack length and vertical displacement of the sample increase. The vertical displacement and crack length are related to each other by the following equation [18]:

$$
\frac{\Delta_{p}}{\Delta_{p}^{\text {nocrack }}}=1+\left[\frac{1.805 P}{E t \pi \Delta_{p}^{\text {nocrack }}}\left(\left|\ln \left\{1-\frac{c}{b}\right\}\right|-\frac{c}{b}\right)\right] x^{2},
$$




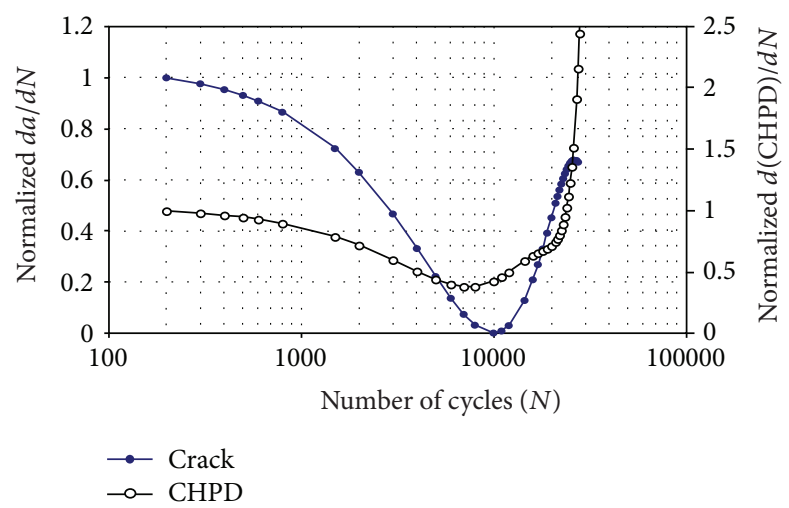

FIGURE 10: Normalized rate of crack growth $(d a / d N)$ and rate of cumulative HPD $(d(\mathrm{CHPD}) / d N)$ for MDOT AC mixtures.

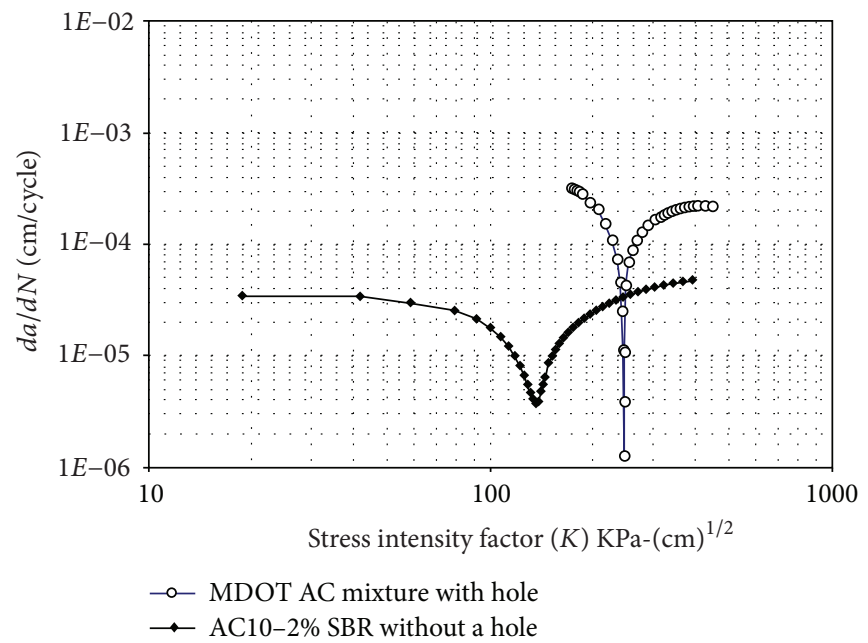

FIGURE 11: $K-d a / d N$ curve for AC10-2\% SBR and MDOT AC mixtures with slot at the center.

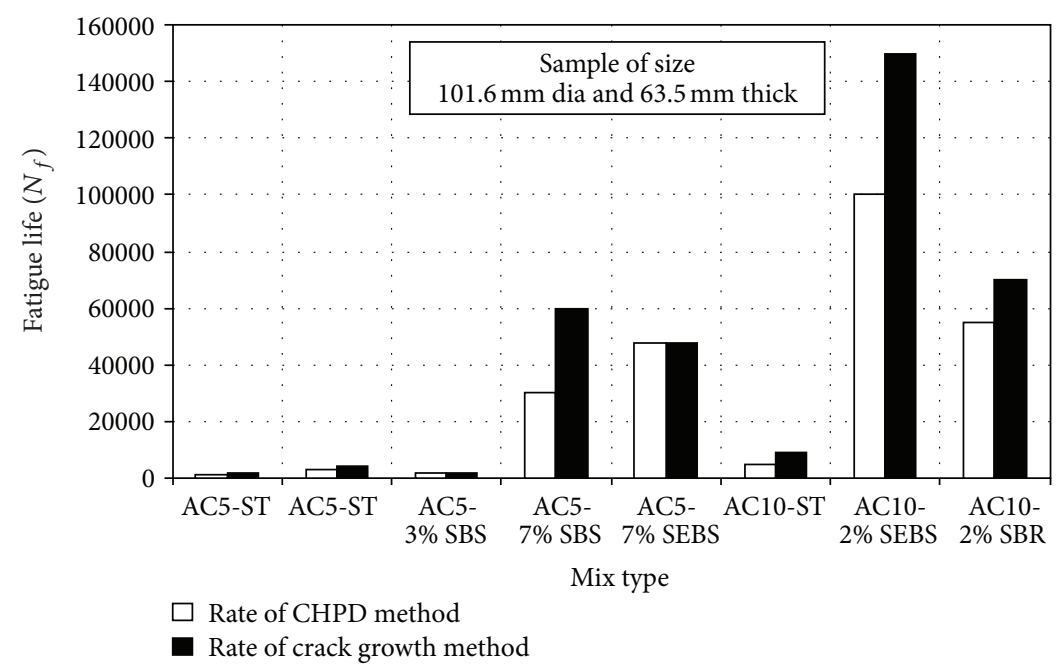

FIGURE 12: Comparison of the fatigue lives between the rate of cumulative HPD and crack growth criteria for AC straight and PMA mixtures. 


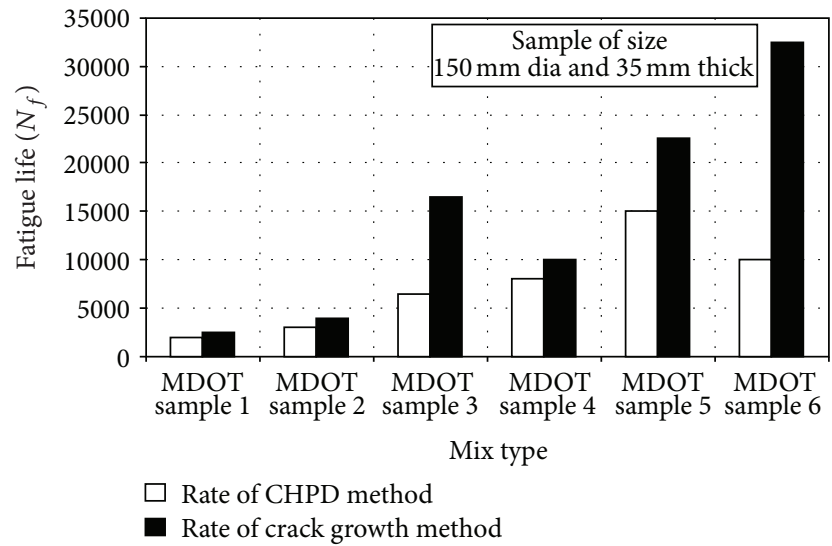

FIGURE 13: Comparison of the fatigue lives between the rate of cumulative HPD and crack growth criteria for MDOT AC mixture with and without slot at the center.

where $\Delta_{p}=$ load point displacement with crack, $\Delta_{p}^{\text {nocrack }}=$ load point displacement with no crack present, $c=$ crack length, $b=$ radius of the sample, $E=$ elastic modulus $t=$ thickness of the sample, and $P=$ applied load.

The load point deflection with no crack present can be obtained from an appropriate analytical expression relating load and load point displacement to material properties and dimensions as

$$
\Delta_{p}^{\text {nocrack }}=\frac{3.59}{E t} P
$$

Rearranging the above two equation will yield

$$
\frac{\Delta_{p}}{\Delta_{p}^{\text {nocrack }}}=1+\frac{1}{\pi}\left(\left|\ln \left\{1-\frac{c}{b}\right\}\right|-\frac{c}{b}\right) .
$$

By using the numerical approach the crack length can be calculated from (14). Once the crack length is known, the $K$ values for each load cycle can be calculated. The $A$ and $m$ material properties can be determined by plotting the $K$ values and rate of crack growth in crack length on log-log scales and can be used for Paris law.

\section{Results and Discussion}

Figure 2 shows the effect of the number of load repetition $(N)$ on the modulus and normalized compliance (NC) of HMA mixture at test temperature of $20^{\circ} \mathrm{C}$. It can be seen that the modulus values decrease and the normalized compliance increases with increasing number of load repetitions. A best-fit polynomial equation was obtained expressing the modulus as a function of the number of load repetition. The normalized compliance of the sample was then calculated by simply taking the inverse of the modulus and dividing the result by the compliance value at the 100th load repetition. The results were plotted as a function of the number of load repetitions and are shown in Figure 2. The normalized compliance increases as the number of cycle increases. Since the normalized compliance and the crack length are uniquely related, the crack length was calculated using (5) and plotted as a function of the number of load repetitions as shown in Figure 3. In order to validate the results the crack length was also calculated using the vertical displacement method (14) and plotted as a function of number of cycles (Figure 3). It can be seen that crack lengths calculated using both fracture mechanics methods are similar. The slight difference may be because of the best-fit curve used to fit the data. The examination of (11) and the data in Figures 2 and 3 indicate that the crack in HMA sample reaches its full length when the compliance is twice the initial value. This implies that when the modulus reaches its 50 percent value due to repeated loadings, the sample completely cracks. It should be noted that 50 percent reduction in modulus has also been used by various researchers as one of the fatigue criteria.

Similarly the measured cumulative HPD was plotted against the number of load repetition as shown in Figure 4. The normalized rates of both crack growth and cumulative HPD with respect to first data point (100th load repetition) were calculated and plotted against the logarithmic value of the number of load repetition as shown in Figure 5. It can be seen that the normalized rate of cumulative HPD decreases first, forms a valley, and then starts to increase. This is due to the initial densification of the sample. Similarly, the normalized rate of crack growth decreases first, reaches a valley, and then increases. The decrease in the rate of crack growth is due to the crack being abstracted or shielded by large aggregates in the HMA mixtures. The crack had to deflect and change its path and propagate around the boundary of the aggregates. This crack deflection is referred to as crack shielding mechanism, which decreases the rate of crack growth. The crack tip shielding mechanisms have also been reported by Hertzberg [19] in polycrystalline alumina under cyclic loading. The crack growth rates were found to decrease with increasing crack length before arresting. When crack reached a critical dimension, it started to accelerate in a similar manner as that shown in Figure 5. Relative to the HMA mixtures, the number of load applications at which the crack starts to accelerate is considered the fatigue life of the HMA mixture. The stress intensity factor $(K)$ was also calculated, and the rate of crack propagation was plotted against the stress intensity factor as shown in Figure 6. Similar results for PMA mixtures without slot and straight MDOT HMA mixtures with slot are shown in Figures 7, 8, 9, 10, and 11. These mixtures showed similar trend as that of the mixtures discussed above. The rate of crack growth decreases first and then starts to increase hence violating the Paris' law, which states that the rate of crack growth increases with the increase in the stress intensity factor and obeys the power law as given below:

$$
\frac{d a}{d N}=A K^{m}
$$

where $A$ and $m$ are material constants.

The decrease in the rate of crack growth may be because there is no single crack, instead, there are many secondary cracks surrounding the main crack. Hence, the crack tip contains many microcracks embedded in the plastic zone. The rate of crack propagation and the path it follows mainly 


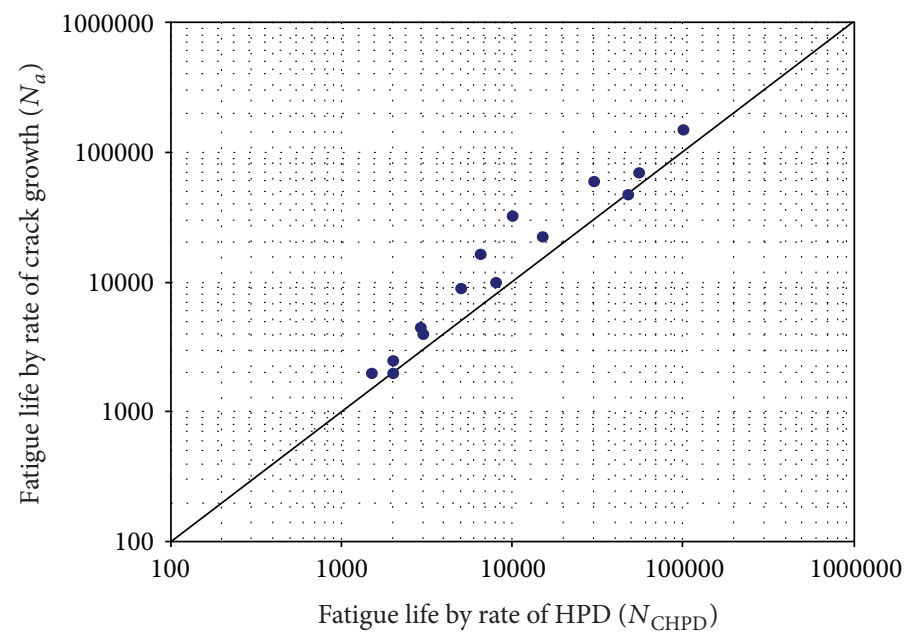

FIGURE 14: Comparison of the fatigue life between the rate of cumulative HPD and crack growth method.
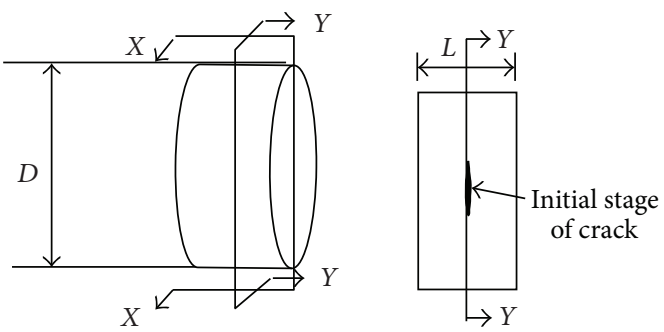

Section $X-X$
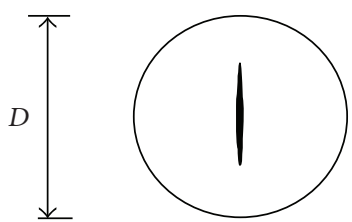

Section $Y-Y$

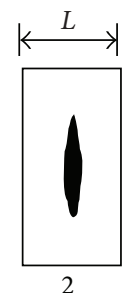

Section $X-X$
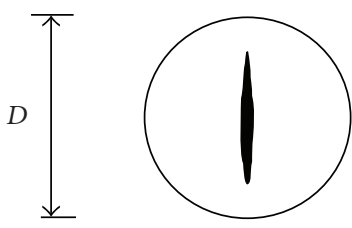

Section $Y-Y$

(a) Crack propagation along vertical and horizontal diameters

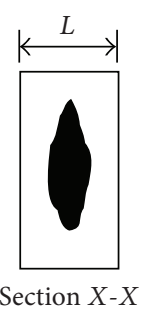

(b) Crack propagation along vertical diameter and thickness

FIGURE 15: Three-dimensional crack propagation model for centrally cracked cylindrical sample under indirect tensile cyclic loading.

depend on the energy balance at the crack tips. Therefore, the energy due to the applied load is utilized by the main crack as well as the microcracks. Further, if there is a large amount of plastic deformation, the crack tips become blunt. Hence, the presence of microcracks and blunting mechanism at the crack tip reduces the effective stress intensity factor and the rate of crack growth $[15,19]$.

The test data was analyzed, and the fatigue lives of all samples were obtained using both criteria. Figures 12 and 13 show that the fatigue life obtained from the rate of crack 
growth criterion was higher than the rate of cumulative HPD criterion. Figure 14 shows the fatigue life calculated using both criteria. It was observed that fatigue life based on the rate of crack growth criterion yielded an average of 45 percent higher values than the rate of accumulation of HPD criterion.

The difference in the fatigue life obtained from the two criteria can be partly explained by the examination of the crack growth criterion. It is based on theory of elasticity with the assumptions that the material is homogeneous, isotropic elastic solid, and there are negligible changes in the material properties during testing. This is not the case for the HMA mixtures, which are heterogeneous mix of asphalt cement and fine and coarse aggregates. Further, the criterion is based on two-dimensional crack growth. For cylindrical sample tested in indirect cyclic tensile loading, the crack propagates in three dimensions. Given that the crack initiates at the center of the sample, the crack will propagate along both the vertical and horizontal diameters as well as along the thickness of the sample as schematically shown in Figure 15. The crack length equation only calculates the crack length along the vertical diameter of the sample. This may result in higher fatigue life relative to the cumulative HPD criterion. On the other hand the rate of accumulation of HPD criterion of fatigue determination is based on direct measurement of HPD from the test sample. Since the fatigue of cylindrical sample is mainly due to the accumulation of HPD, the rate of accumulation of HPD is a true representation of fatigue crack growth. This criterion produced consistent and repeatable results for both straight and PMA mixtures [5].

\section{Conclusions}

In this paper, a comparison between two different fatigue life criteria for two-dimensional problems represented by cylindrical samples are discussed and presented. One criterion was based on the rate of accumulation of the tensile horizontal plastic deformation (HPD) as a function of the number of load repetitions. The other criterion was based on fracture mechanics and takes into account stress intensity factor and the rate of crack growth with respect to the number of load repetitions. Indirect tensile cyclic loading test was conducted on straight and PMA-modified HMA mixtures with and without slot at the center of sample. It was found that the crack in HMA sample reaches its full length when the compliance is twice of its initial value. The rate of crack growth criterion showed higher fatigue life relative to the rate of accumulation of horizontal plastic deformation. This difference was attributed to the three-dimensional nature of crack propagation. Nevertheless, the rate of accumulation of HPD criterion produced consistent and repeatable results and is recommended to be used for the determination of laboratory fatigue life of HMA mixtures.

\section{Acknowledgment}

The authors wish to express their sincere thanks to the Pavement Research Center of Excellence at Michigan State University and Michigan Department of Transportation for sponsoring this study. Special thanks are also extended to the project review committee for their valuable feedback.

\section{References}

[1] G. Baladi, "Fatigue life and permanent deformation characteristics of asphalt concrete mixes," Transportation Research Record, no. 1227, pp. 75-87, 1989.

[2] Y. R. Kim, "Effect of temperature and mixture variables on fatigue life predicted fatigue testing," Transportation Research Record, no. 1317, 1991.

[3] A. A. Tayebali, J. B. Sousa, and G. M. Rowe, "Fatigue response of asphalt-aggregate mixtures," Journal of the Association of the Asphalt Paving Technologists, vol. 61, pp. 333-360, 1992.

[4] G. Y. Baladi, "Integrated material and structural design method for flexible pavements. Vol. 1," Report. RD-88-109, FHWA, U.S. Department of Transportation, 1988.

[5] M. J. Khattak and G. Y. Baladi, "Engineering properties of polymer-modified asphalt mixtures," Transportation Research Record, no. 1638, pp. 12-22, 1998.

[6] C. Monismith and J. A. Deacon, "Fatigue of asphalt paving mixtures," Transportation Engineering Journal, vol. 95, no. 2, pp. 317-346, 1969.

[7] M. Pell and K. Cooper, "The effect of testing and mix variables on the fatigue performance of bituminous materials," Proceedings of the Association of Asphalt Paving Technologists, vol. 44, pp. 1-37, 1975.

[8] J. Alonso, Estudio del proceso de deformación y agrietamiento por fatiga de mezclas bituminosas sometidas a cargas cíclicas [Doctoral Dissertation], Universidad Politécnica de Cataluña, 2006.

[9] H. Di Benedetto, C. de la Roche, and L. Francken, "Fatigue of bituminous mixtures: different approaches and RILEM interlaboratory tests," in Proceedings of the 5th International RILEM Symposium on Mechanical Tests for Bituminous Materials (MTBM '97), pp. 15-26, Lyon, France, 1997.

[10] H. Baaj, Comportement á la fatigue des matériaux granulaires trités aux liants hydrocarbons [Doctoral Dissertation], INSA, Villeurbanne, France, 2002.

[11] O. J. Reyes-Ortiz, A. E. Alvarez-Lugo, and P. Limon, "Effect of the failure criterion on the laboratory fatigue response prediction of hot mix asphalt mixtures," Dyna, vol. 79, no. 174, pp. 31-39, 2012.

[12] F. E. Perez, R. Miro, A. Martinez, and J. Alonso, "Desarrollo de un nuevo procedimiento para la evaluación del comportamiento a fatiga de las mezclas bituminosas a partir de su caracterización en un ensayo a tracción," in Primer Premio Internacional a la Innovación en Carreteras-Asociación Española de la Carretera, Madrid, Spain, 2006.

[13] J. N. Goodier and N. J. Hoff, "Structural mechanics," in Proceedings of 1st Symposium on Naval Strcutural Mechanics, Pergamon Press, New York, NY, USA, 1960.

[14] Y. H. Haung, Pavement Analysis and Design, Prentice Hall, Englewood Cliffs, NJ, USA, 1993.

[15] K. Majidzadeh, E. M. Kuaffmann, and D. V. Ramsamooj, "Application of fracture mechanics in the analysis of pavement fatigue," in Proceedings of the Association of Asphalt Paving Technologists, vol. 40, pp. 227-246, 1971.

[16] D. Broek, The Practical Use of Fracture Mechanics, Kluwer Academic, Boston, Mass, USA, 1988. 
[17] D. P. Rooke and D. J. Cartwright, Compendium of Stress Intensity Factor, London Her Majesty's Stationary Office, 1976.

[18] J. M. Read and A. Collop, "Practical fatigue characterization of bituminous paving mixtures," in Association of Asphalt Paving Technologists Technical Sessions (AAPT '97), vol. 66, Salt Lake City, Utah, USA, 1997.

[19] R. W. Hertzberg, Deformation and Fracture Mechanics of Engineering Materials, John Wiley \& Sons, New York, NY, USA, 1989. 

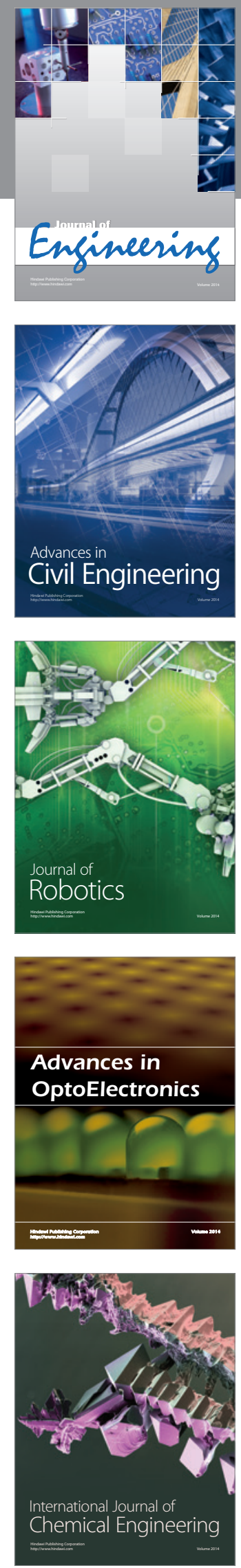

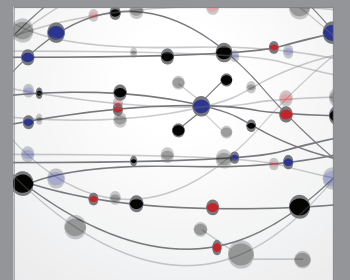

The Scientific World Journal
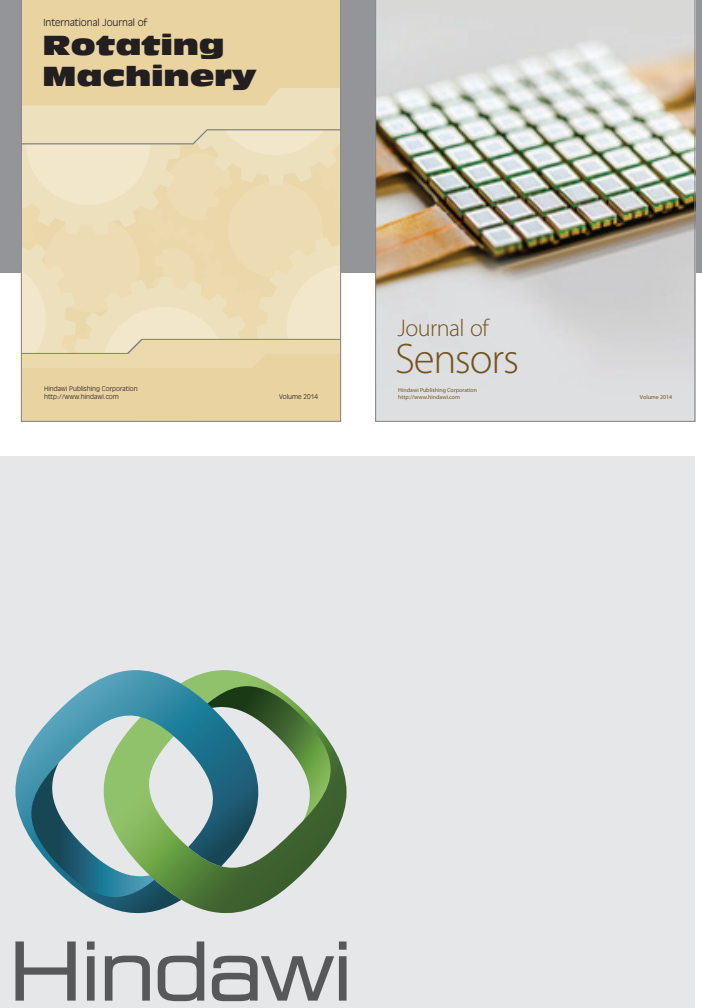

Submit your manuscripts at http://www.hindawi.com
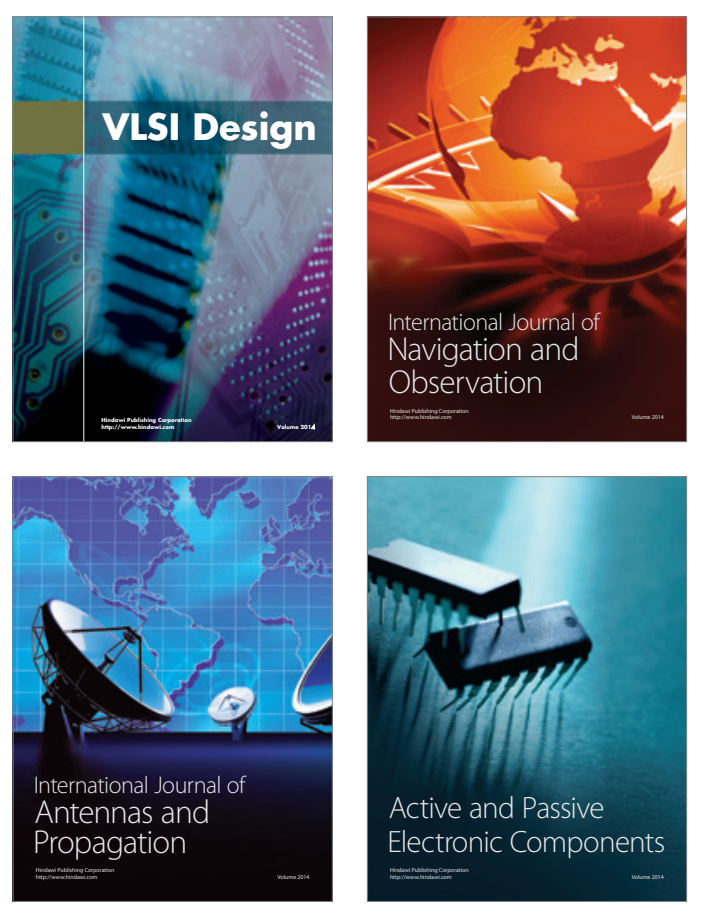
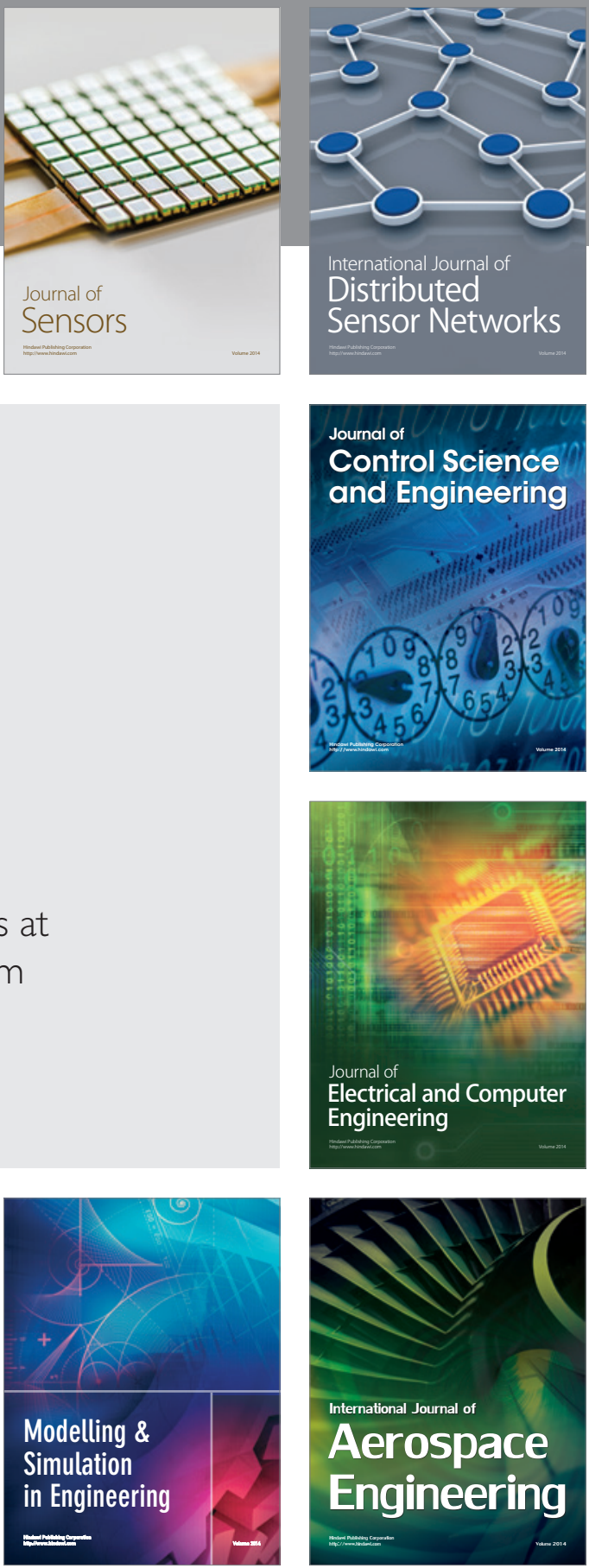

Journal of

Control Science

and Engineering
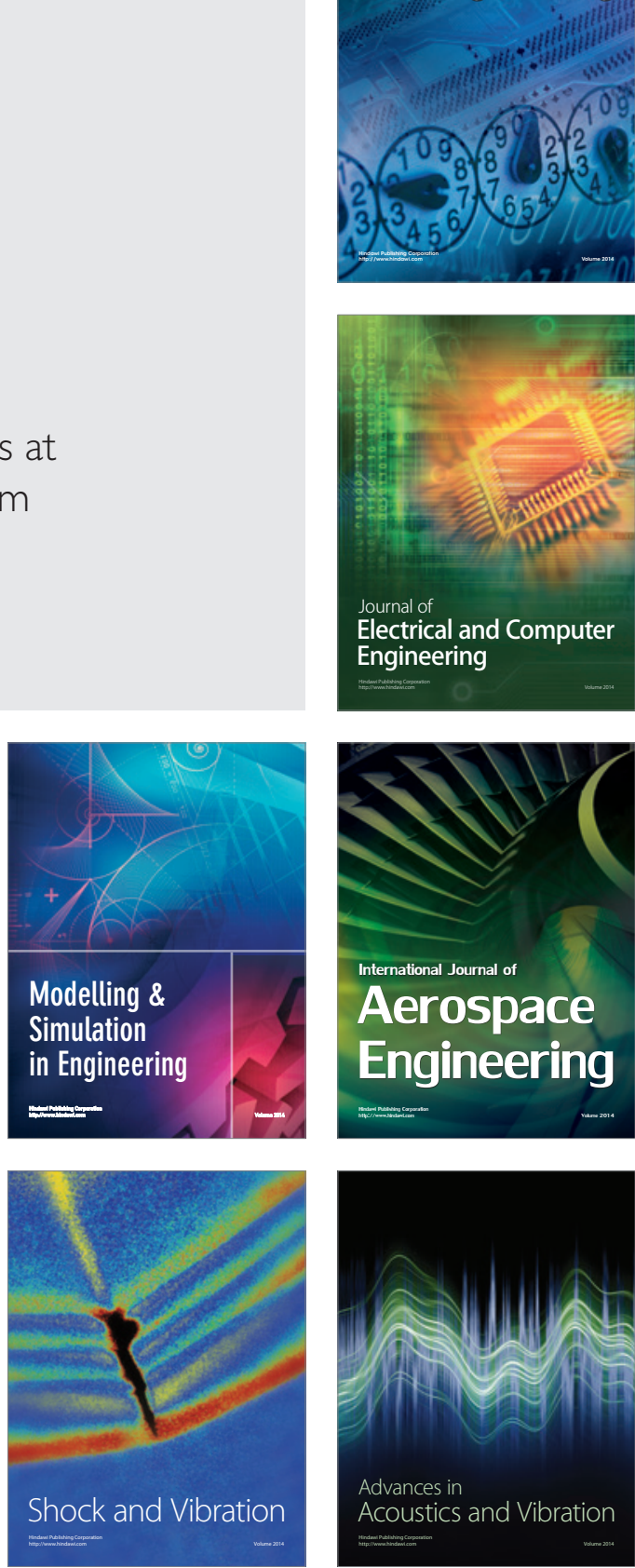